East African Medical Journal Vol. 81 No. 4 April 2004

PREVALENCE OF HEPATITIS A, B, C AND HUMAN IMMUNODEFICIENCY VIRUS SEROPOSITIVITY AMONG PATIENTS WITH ACUTE ICTERIC HEPATITIS AT THE KENYATTA NATIONAL HOSPITAL, NAIROBI

J. O. Atina, MBChB, MMed, Senior House Officer, E. O. Ogutu, MBChB, MMed, Associate, Professor and Consultant Gastroenterologist, Department of Medicine, College of Health Sciences, University of Nairobi, P.O Box 19676, Nairobi, Kenya, W. G. Hardison, MD, Professor of Medicine and Gastroenterology and (Emeritus), University of California, San Diego, Honorary Lecturer, Department of Medicine, University of Nairobi, and J. Mumo*, BSc, MSc., PhD., Associate Professor of Immunology, Department of Human Pathology, College of Health Sciences, University of Nairobi, P.O. Box 19676, Nairobi, Kenya *Deceased

Request for reprints to: Dr. J. O. Atina, Kenyatta National Hospital, P. O. Box, 19314, 00202, Nairobi, Kenya

\title{
PREVALENCE OF HEPATITIS A, B, C AND HUMAN IMMUNODEFICIENCY VIRUS SEROPOSITIVITY AMONG PATIENTS WITH ACUTE ICTERIC HEPATITIS AT THE KENYATTA NATIONAL HOSPITAL, NAIROBI
}

\section{J. O. ATINA. E. O. OGUTU. W. G. HARDISON and J. MUMO*}

\begin{abstract}
Objective: To determine the prevalence of hepatitis A, B, C and HIV seropositivity among patients with acute icteric hepatitis.

Design: Cross-sectional descriptive survey.

Setting: Kenyatta National Hospital, Nairobi.

Subjects: Eighty four patients aged above six months with a history of jaundice not exceeding six months were recruited. There were 47 males and 17 females with an age range of eight months to 67 years and a median age of 25 years.

Methods: History was obtained physical examination done and blood taken for determination of bilirubin, ALT, AST and ALP levels. Sera that had disproportionately greater transaminase than ALP elevation were assayed for IgM anti-HAV, IgM antiHBc, HbsAg, anti-HCV and anti-HIV antibodies.

Results: Evidence of hepatitis $A, B$, and $C$ was round in $41.7 \%, 26.2 \%$, and $7.1 \%$ of the patients respectively, $13.1 \%$ of the patients were HBsAg carriers while $30.1 \%$ of all patients were HIV positive. Thirty two patients did not have evidence of hepatitis A, B, or $\mathrm{C}$ infection and this group was significantly associated with HIV infection $(p=0.003)$. Conclusion: Hepatitis A was the commonest overall type of acute icteric hepatitis seen at the KNH, and among patients aged 15 years and below. Hepatitis B was the leading identified cause of acute hepatitis among those aged over 15 years. Hepatitis $\mathrm{C}$ accounted for $7.1 \%$ of acute icteric hepatitis $30.1 \%$ of all patients and $50 \%$ of those admitted with acute hepatitis were also HIV positive.
\end{abstract}

\section{INTRODUCTION}

Acute viral hepatitis is most often caused by the hepatitis viruses $\mathrm{A}, \mathrm{B}$ and $\mathrm{C}(1)$. The contribution of these viruses to clinical disease varies widely in different parts of the world and also changes over time.

The first prevalence study of acute viral hepatitis in Kenya was done by Bagshawe et al. in 1971(2). They screened for the HBsAg among patients with liver disease at the $\mathrm{KNH}$ and found it in $54 \%$ of acute hepatitis cases. The second study was done by Greenfield(3) in 1982 and looked at adults with acute sporadic hepatitis at the Kenyatta National Hospital $(\mathrm{KNH})$. Hepatitis A, B and non-A, non-B accounted for $12 \%, 70 \%$ and $18 \%$ respectively. Neither study evaluated for hepatitis $\mathrm{C}$ which was at that time not known and therefore had no diagnostic tests. It is now recognised that hepatitis $\mathrm{C}$ formed part of what was previously called non-A non-B hepatitis.

The advent of HIV raises the issue of HIV/ hepatitis virus co-infection. Several outbreaks of hepatitis
A have been reported in homosexual men and intravenous drug users who are also HIV positive(4). Hepatitis B is said to be common in HIV infected persons; in one study over $90 \%$ of patients with HIV had HBV markers of current or past infection(5). Hepatitis C in HIV infected people causes severer and more rapidly progressive disease with the duration to development of cirrhosis being as low as three years(6). HCV/HIV co-infected people are also more likely to develop liver failure(7).

\section{MATERIALS AND METHODS}

Study Population: This study was carried out in the year 2000 at the Kenyatta National Hospital, which is a teaching and referral hospital in the city of Nairobi. Most of the patients seen at the hospital who came from the city and surrounding districts belong to the lower socio-economic class.

Patient recruitment: Consecutive patients with acute icteric hepatitis (defined as the presence of a history of jaundice for a period not exceeding six months together with 
a disproportionately greater transaminase than alkaline phosphatase elevation) referred to the liver clinic or admitted in the medical and paediatric wards were recruited if they met the inclusion criteria of the study.

Patients of both sexes aged over six months were included in the study if they had a diagnosis of acute hepatitis as defined above and they (or their parents or guardians in the case of minors) gave informed written consent to participate in the study. Patients who had features of chronic liver disease including liver neoplasms and those who declined to give consent were excluded from the study.

All recruited patients had their ages, sex and case histories recorded on an already prepared data sheet. Each patient then had a physical examination and the findings were recorded similarly.

Laboratory methods: The serum aspartate transaminase (AST) level was determined using the Karmen technique(8) as modified by Bergmeyer et al(9). Alanine transaminase (ALT) was measured by the Wroblewski technique(10) as modified by Bergmeyer et al(9). Alkaline phosphatase (ALP) was assessed using the ALP Study Group recommended method(11). The total serum bilirubin was determined using the method of Van den Bergh and Muller(12) as modified by Pearlman(13), the direct using the method of Keller (14), and the indirect by subtraction(15).
Thereafter IgM anti-hepatitis A (IgM anti-HAV). IgM anti-hepatitis B core (IgM anti-HBc), and total anti-hepatitis $\mathrm{C}$ antibodies (anti-HCV) (4th generation) as well as HIV1 and HIV-2 antibodies were done using ELISA kits(16). HBsAg was assayed for using a reverse passive haemagglutinition method(17).

Ethical considerations: The study was carried out with the approval of the Ethical and Scientific Review Committee of the KNH. Pre-and post-test counseling for the HIV test was done.

Data analysis: Data was analysed with SPSS 10.0 computer software. The $95 \%$ confidence level was used to assess statistical significance. The Pearson chi-square test was utilised in assesing statistical significance of association.

\section{RESULTS}

Eighty four patients were enrolled into the study; forty seven males and thirty seven females. The age range was eight months to 67 years with a mean of 25.98 a median of 25 and a standard deviation of 16.59 years. Twenty four patients were aged 15 years and below. The baseline characteristics are shown in Table 1.

Table 1

Baseline patients characteristics

\begin{tabular}{lll}
\hline Characteristic & No. & $(\%)$ \\
\hline Sex & & \\
$\quad$ Male & 47 & 56 \\
$\quad$ Female & 37 & 44 \\
Age (years) & & \\
$\quad$ 15 and below & 24 & 28.6 \\
$\quad$ Above 15 & 60 & 71.4 \\
Site management & & \\
$\quad$ Inpatient & 56 & 66.7 \\
$\quad$ Outpatient & 28 & 33.3 \\
Marital Status (of patients aged $>15$ years) & & \\
$\quad$ Married & 34 & 40.5 \\
$\quad$ Single & 26 & 31 \\
Residence & & \\
$\quad$ Rural & 21 & 25 \\
$\quad$ Urban & 63 & 75 \\
\hline
\end{tabular}

Table 2

Liver function tests

\begin{tabular}{lllllll}
\hline & \multicolumn{2}{c}{ Bilirubin } & \multicolumn{2}{c}{ Serum enzymes } \\
\cline { 2 - 7 } & $\begin{array}{l}\text { Total } \\
(\boldsymbol{\mu} \mathrm{mol} / \mathrm{L})\end{array}$ & $\begin{array}{l}\text { Conjugated } \\
(\boldsymbol{\mu} \mathrm{mol} / \mathrm{L})\end{array}$ & $\begin{array}{l}\text { Unconjugated } \\
(\boldsymbol{\mu} \mathrm{mol} / \mathrm{L})\end{array}$ & $\begin{array}{l}\text { ALT } \\
(\mathrm{iu} / \mathrm{L})\end{array}$ & $\begin{array}{l}\text { AST } \\
(\mathrm{iu} / \mathrm{L})\end{array}$ & $\begin{array}{l}\text { ALP } \\
(\mathrm{iu} / \mathrm{L})\end{array}$ \\
\hline Mean & 182.3 & 75.5 & 104.3 & 144.8 & 271.4 & 593.2 \\
SD & 162.4 & 72.2 & 97.6 & 118.1 & 299.2 & 476.6 \\
Normal values & $<18.8$ & $<4.3$ & $<14.5$ & $<42$ & $<37$ & $80-306$ \\
\hline
\end{tabular}


Table 3

Viral markers

\begin{tabular}{|c|c|c|c|c|c|c|}
\hline Marker & IgM Anti-HAV & IgM Anti-HBc & HBsAg & Anti-HCV & Anti-HIV $1 \& 2$ & Others \\
\hline Number & 35 & 22 & 21 & 6 & 26 & 32 \\
\hline $\begin{array}{l}\text { Patients } \\
15 \text { years } \\
\text { and below }(\%)\end{array}$ & 67.9 & 7.1 & 25 & 10.7 & 7.7 & 12.5 \\
\hline $\begin{array}{l}\text { Patients } \\
\text { above } 15 \text { years }(\%)\end{array}$ & 23.9 & 29.9 & 75 & 4.5 & 92.5 & 87.5 \\
\hline$\%$ of total & 41.7 & 26.2 & 25 & 7.1 & 31 & 38.1 \\
\hline
\end{tabular}

Figure 1

Age distribution of patients with the various types of hepatitis

Figure 2

HIV seropositivity

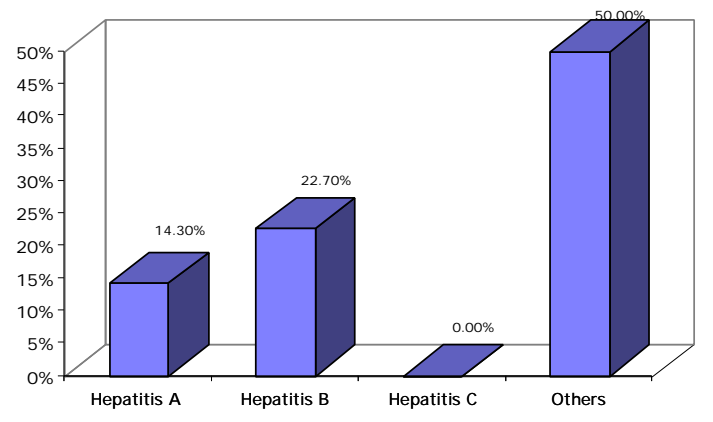

The mean duration of jaundice from the time it was first noticed to the time the patients were recruited into the study was 17.43 days. The mean for female patients was 15.39 days and for male patients 19.11 days. The liver function test results are shown in Table 2. Sixty three patients tested positive for one or more serological markers of acute hepatitis A, B and C. No markers were detected in 32 patients. The number of patients testing positive for the various markers of acute infections is shown in Table 3.

Eleven patients tested positive for markers of acute infection of more than hepatitis virus. Seven patients had both hapatitis A and B, two had A and C, while one had B and $\mathrm{C}$. One patient had triple infection with hepatitis A, B and C. Eleven patients had the HBsAg with negative IgM anti-HBc test. These made up $13.1 \%$ of all patients and were considered carriers. The distribution of HIV seropositivity among patients with various hepatitis types is shown in Figure 1.

\section{DISCUSSION}

The mean transaminase levels in this study were much lower than figures reported in literature(1) with an AST to ALT ratio of 1.8. Transaminase levels are known to peak at the onset of jaundice and fall 
progressively thereafter(1). These low levels could be attributed to the rather long average duration of jaundice of 17.43 days before patients were recruited into the study. The AST to ALT ratio is typically less than one in acute viral hepatitis (18) though occasionally the ratio may be higher and even exceed two (19). The ratio in this study was comparable to one of 1.8 reported by Lodenyo et al (20) in a similar study done in South Africa.

Hepatitis A was the leading cause of acute icteric hepatitis overall, accounting for $41.7 \%$ of all patients studied. Among those aged 15 years and below it accounted for $67.9 \%$ of all cases of hepatitis. On the other hand it accounted for only $23.9 \%$ of all cases of hepatitis among those older than 15 years, almost twice the $12 \%$ rate reported by Greenfield (3). This could perhaps be attributed to the mushrooming of slums, overcrowding and sanitation inadequacies in Nairobi in the two decades since the Greenfield study was done. Studies from other parts of the world have found hepatitis A to account for between $3.6 \%$ and $66.4 \%$ of overall acute sporadic hepatitis(21-25).

That hepatitis $A$ is the predominant type of hepatitis in childhood in this country is also borne out by a 1990 community sero-prevalence survey for the markers of hepatitis A infection in Kiambu district, which borders Nairobi, where $80 \%$ of children below four years of age were found to have evidence of previous disease(26). Studies from other parts of the developing world have also found hepatitis A to be a disease of the young as was found, for instance, by Wang et al (23) in Taiwan where the disease occurred mainly in youngsters and its prevalence decreased with increasing age. Hepatitis $\mathrm{A}$ is more common among the young because it is mainly spread faeco-orally and this age group may be unable to maintain good hygiene standards.

Acute hepatitis B was the second most common type of hepatitis overall, affecting $26.2 \%$ of all patients. This is comparable to rates reported from other parts of the developing world(23,25,27,28). Among people over 15 years of age, acute hepatitis B was the leading cause of hepatitis, being diagnosed in $29.9 \%$ of them. This suggests that sexual activity and other parenteral modes of transmission of HBV start after 15 years of age. There is a marked fall in overall prevalence of hepatitis B from the 70\% Greenfield found in 1982(3). This is probably due to the decline of such risky traditional practises as mass circumcision and tribal scarification.

Thirteen percent of all patients studied were HBsAg carriers. This figure is comparable to the $14 \%$ found by Greenfield in 1983(3) and lies well within the $5-15 \%$ HBsAg carrier rate reported by Okoth and colleagues for the Nairobi province of Kenya(29). Carriage rates globally vary from $8 \%$ to $53 \%(21,22,28)$.

Six patients $(7.1 \%)$ had hepatitis $\mathrm{C}$ one of whom was in hepatic encephalopathy, and passed away soon after being recruited. These results confirm what has been reported elsewhere that HCV rarely causes acute icteric hepatitis(30). However they do show that the disease can be serious and even fatal. The overall proportion of patients with acute hepatitis $\mathrm{C}$ compares very well with figures reported from the rest of the world. Alter(25) has reported $4.4 \%$ from the USA, Saat et al(21) 5.4\% from Malaysia, Wang et al(23), 9.9\% from China, and the $\mathrm{WHO}(24) 10.3 \%$ from Japan. Ethiopia has been reported to have a much higher hepatitis C prevalence of 19\%(31).

Thirty eighty point one percent of the patients did not have hepatitis A, B or C viral makers. This group had a statistically significant association $(p=0.003)$ with HIV seropositivity. This suggests the posibility of infection by opportunistic organisms that have been shown to affect the liver in HIV positive individuals(32).

Twenty six patients were infected with the HIV virus. Among admitted adults with hepatitis, the HIV seropositivity rate was $50 \%$. This was much higher than the $19 \%$ seroprevalence rate for admitted patients in the medical wards at the KNH reported by Gilks et al (33). Similarly high HIV seroprevalence rates have been found among admitted patients with various disorders in the same hospital $(34,35)$. Among admitted children in the study only one was HIV seropositive, representing $8.3 \%$. This is comparable to the $12.7 \%$ reported by Mugo et al (36) among admitted children at the $\mathrm{KNH}$.

The HIV co-infection rates with hepatitis $\mathrm{A}, \mathrm{B}$, $\mathrm{C}$ and other unspecified types were $19.2 \%, 22.7 \%, 0 \%$ and $50 \%$ respectively. A South African study by Lodenyo et al (20) found HBV/HIV and HCV/HIV coinfection rates of $41 \%$ and $1 \%$ respectively.

\section{ACKNOWLEDGEMENTS}

To Mr. Kahara of the Immunomolecular Diagnostic Laboratory for running the liver function tests; Mrs. Kimani, Mrs. Karimi and Mr. Kilonzo of the Immunology Laboratory for the serological assays; Dr. Okoth and Mr. Kaiguri for the HBsAg assays that were done at the KEMRI hepatitis laboratory free of charge; and Aventis Pasteur SA (East Africa) and GlaxoSmithKline for financial assistance.

\section{REFERENCES}

1. Hsu, H. H., Feinnstone, S. M., and Hoofnagle, J. H.: Acute viral hepatitis in Mendel, Douglas and Bennett's Principles and Practise of Infectious Diseases, $4^{\text {th }}$ ed. Mendell GL, Bennet, J. E., Dolin, R., Editors. Churchill Livingstone. 1995.

2. Bagshawe, A. F., Parker, A. M. and Jordan, A. Hepatitis associated antigen in liver disease in Kenya. Brit. Med. J. 1971; 1:88-89.

3. Greenfield, C.: Some epidemiological and molecular aspects of hepatitis in Kenya. MD thesis, University of Glasgow.1985.

4. Namwani, Coswell S., Boag F. et al. Hepatitis A 
seroprevalence in heterosexual and homosexual men. Genitourin Med. 1994; 70:325-328.

5. Lebovics, E., Dworkin, B. Heier, S., and Rosenthal, W. The hepatobiliary manifestations of HIV infection. Amer. J. Gastroenterol. 1988; 83:1-7.

6. Martin, P., DiBisceghe, A. M., Kassiamides, C. et al. Rapidly progressive non-A non-B hepatitis in patients with HIV infection. Gastroenterol. 1989; 97:1559-1561.

7. Eyster, M. E., Diamondstone, L. S. et al. Natural history of HCV infection in multi-transfused hemophiliacs; effect of co-infection with HIV. J. AIDS 1993; 6:602-610.

8. Karmen, A. A note on the spectrophotometric assay of glutamic oxaloacetate transaminase in human blood serum. J. Clin. Invest. 1955; 34:131.

9. Bergmeyer, H. U., Scheibe, P., and Wahlefeld, A. W. Optimization of methods for aspartate aminotransferase and alanine aminotransferase. Clin. Chem. 1978; 24: 58-73.

10. Wroblewski, F. and LaDue, J. Serum glutamic pryuvate transminase in cardiac and in hepatic disease. Proc. Soc. Exper. Biol. and Med. 1956; 91:569.

11. Alkaline Phosphatase Study Group, Committee on standards of the AACC, Subcommittee on Enzymes, Tietz, W. (Chairman) et al. Progress in the development of a recommended method for alkaline phosphatase activity measurements. Clin. Chem. 1980; 20:1023.

12. Van den Bergh, A. A. H., and Muller, P. Uber eine direct und eine indirecte Diazoreaktion auf Bilirubin. Biochem Z. 1916; 77:90-103.

13. Pearlman, F. C., and Lee, R. T. Y.: Detection and measurement of total bilirubin in serum with use of surfactants and solubilizing agents. Clin. Chem. 1974; 20:447-453.

14. Keller, H.: Analyse, Befund, Interprtation. Georg Thiema Verlag, Stuttgart. 1886; 246.

15. Friedman, L. S., Martin, P., and Munoz, S. J. Liver function tests and the objective evaluation of the patient with liver disease in Hepatology, A textbook of liver disease, 3rd edition, Page 798. David Zakim, Thomas Boyer (Editors), W. B. Saunders Company. 1996.

16. Engrall, E., and Perlmann, P. Enzyme linked immunorsobent assay. Quantitative assay of immunoglobulin G. Immunochemistry. 8:874-887.

17. Okoth, F. A., Kaiguri, P. M., Mathenge, E., et al. KEMRI Hepcell II Hepatitis B surface antigen screening kit. East. Afr. Med. J. 1999; 76:530-532.

18. Bates, B., and Yellin, J. A. The yield of multiphasic screening JAMA 1972; 222:74.

19. De Ritis, F., Coltorti, M., and Guisti, G. Serum transaminase activities in liver disease. Lancet 1972; 1:685.

20. Lodenyo, H., Schoub, R, Ally, R., Kairu, S., and Segal, I. Hepatitis B and C virus infections and liver function in AIDS patients at Chris Hani Baragwanath Hospital, Johannesburg. East. Afr. Med. J. 2000; 77:13-15.
21. Saat, Z., Sinniah, M., Kin, T. L., Baharuddin, R., et al: A four year review of acute viral hepatitis cases in the east coast of peninsular Malaysia. Southeast J. Trop. Med. and Publ. Health 1999; 30:106-109.

22. Chu, C. M., Lin, S. M., Hsieh, S. Y., et al. Etiology of sporadic acute viral hepatitis in Taiwan. J. Med. Virol. 1999; 58:154-159.

23. Wang, Y., Han, W., and An, Y.: Studies on serotyping of sporadic acute viral hepatitis. Chung-hua yu fang $i$ hsueh tsa chih. 1997, 31:147-148.

24. Weekly epidemiological record. WHO Geneva 21 June 2000: No 3:18-19.

25. Alter, M. J. Acute viral hepatitis in the United States of America. American Association for the Study of Liver Disease: Postgraduate course 2000: Update on Viral Hepatitis. Oct. 27-28 2000. Wyndham Anatole Hotel, Dallas, Texas.

26. Okoth, F. A., Yamanaka, I., Takayanagi, N., et al. A commumity based longitudinal study of viral hepatitis B in a rural community. East Afr. Med. J. 1990: 62:640-649.

27. Topley, J. N. Acute jaundice in Zimbabwean children. East. Afr. Med. J. 1987; 64:849-853.

28. Hazra, B. R., Saha, S. K., Mazunder, A. K. et al: Incidence of HBV infection amongst clinically diagnosed acute viral hepatitis cases and relative risk of development of $\mathrm{HBV}$ infection in high-risk groups in Calcutta. Indian J. Public Health 1998: 42:56-58.

29. Okoth, F. A. Viral hepatitis. East Afr. Med. J. 1996: 73: 308-312.

30. Sherlock, S.: Clinical features of hepatitis in Viral Hepatitis, $2^{\text {nd }}$ edition, Pg 7 Arie Zuckennan, Howard C Thomas Eds Churchill Livingstone.

31. Tsega, E., Hansson, B. G., Krawozynski, K., and Nordenfelt, E. Acute sporadic viral hepatitis in Ethiopia: causes, risk; factors, and effect on progression. Clin. Infec. Dis. 1997; 14:1961.

32. Piralvisuth, T., Siripaitoon, P., Sriplug, H., and Ovartlampom, B: Findings and benefit of liver biopsies in 46 patients infected with HIV. J. gastroenterology and hepatology. 1999; 14:146-149.

33. Gilks, F. C., Brindle, R. J., Lule, G. N., et al. Lifethreatening bacteraemia in HIV-1 seropositive adults admitted to hospital in Nairobi, Kenya. Lancet 1990; 335:387-390.

34. Owino, E. A. The prevalence of HIV infection and its impact on clinicopathological aspects of exudative pleural effusions in adult patients seen at $\mathrm{KNH}$. MMed thesis, University of Nairobi. 1995.

35. Hooker, J. A. G. Tuberculous meningitis as seen at KNH. MMed thesis, University of Nairobi. 1999.

36. Mugo, J. W., Wafula E., Ngacha, D. M., Plummer, F. A., et al. HIV seropositivity in children aged 6 to 84 months at KNH. Proc. of the KEMRI/KETRIAnnual Med. Scientific Conf. 1997; 13:14-17. 